\title{
Risk premium: insights over the threshold
}

\author{
José L. B. Fernandes ${ }^{\mathrm{a}, \mathrm{b}, *}$, Augusto Hasman ${ }^{\mathrm{a}}$ and \\ Juan Ignacio Peña ${ }^{a}$ \\ ${ }^{a}$ Department of Business Administration, Universidad Carlos III de Madrid, \\ Calle Madrid 126, 28903 Getafe (Madrid), Spain \\ ${ }^{\mathrm{b}}$ Banco Central do Brasil
}

The aim of this article is 2-fold: first to test the adequacy of Pareto distributions to describe the tail of financial returns in emerging and developed markets, and second to study the possible correlation between stock market indices observed returns and return's extreme distributional characteristics measured by Value at Risk and Expected Shortfall. We test the empirical model using daily data from 41 countries, in the period from 1995 to 2005. The findings support the adequacy of Pareto distributions and the use of a log linear regression estimation of their parameters, as an alternative for the usually employed Hill's estimator. We also report a significant relationship between extreme distributional characteristics and observed returns, especially for developed countries.

\section{Introduction}

Financial risk management is closely related with extreme events and so is highly concerned with profit and loss distribution's tail quantiles (e.g. the value of $x$ such that $P(X>x)=0.05)$ and tail probabilities (e.g. $P(X>x)$, for a large value of $x$ ). No matter whether we are concerned with market, credit or other financial risks, one of the main challenges is to model the unusual but really damaging events to permit measurement of their consequences. Specifically in this article we deal with market risk, say the day-to-day determination of the losses we may incur on a trading book due to adverse market movements.

Recent literature (see for instance Embrechts et al., 1997) claims that extreme value theory (EVT) holds promise for accurate estimation of extreme quantiles and tail probabilities of financial asset returns, and hence could be a relevant tool for the management of extreme financial risks. This theory posits that methods based around assumptions of normal distributions are likely to underestimate tail risk. The key idea of EVT is that one can estimate extreme quantiles and probabilities by fitting a model to the empirical survival function (defined as $1-F^{*}(x)$ where $F^{*}(x)$ is the empirical cumulative probability function) of a set of data using only the extreme event data rather than all the observed data available, thereby describing the tail and just the tail, which is the main concern in the extreme events risk management. However, Diebold et al. (1998) describe several pitfalls in the use of EVT in risk management. Also, up to now the question whether the market is compensating for extreme risk factors is still not answered.

In this article, we address one of those pitfalls related to the estimation by $\log$ linear regression of

*Corresponding author. E-mail: jluiz.fernandes@bcb.gov.br 
the parameters of the Pareto distribution and study if there is a risk-premium associated to extreme risk measures [Value-at-Risk (VAR) and Expected Shortfall (ES)], considering developed and emerging markets. We test the empirical model using daily data from 41 countries obtained from Morgan Stanley Capital International (MSCI). The findings support the use of a $\log$ linear regression estimation of the parameters, as an alternative for the Hill's estimator (Maximum Likelihood Estimator). Related to risk premium determinants, we present empirical evidence suggesting significant relationship between extreme distributional characteristics and observed returns, especially for developed countries.

The remaining part of this article is as follows. In Section II we provide a literature review of topics concerning VAR, ES and cross section of average returns' explanations. In Section III the theoretical framework is shown and in Section IV, we describe methodology analysing the main results. Section V concludes.

\section{Literature Review}

Already considered a stylised fact, asset prices in financial markets are characterized by presenting a higher probabilistic density on the tails of its returns' distribution than the Normal distribution and this effect is more salient in emerging markets, in comparison with developed markets; a phenomenon known as 'fat tails'. Extreme value theory has extensively been applied in such context in order to adjust the measure of those assets' VAR.

McNeil (1999) presents an overview of EVT as a method for modelling and measuring extreme risk, in particular showing how the Peaks-Over-Threshold (POT) method may be embedded in a stochastic volatility framework to deliver useful estimates of VAR and ES, a coherent alternative for measuring market risk. ${ }^{1}$ Embrechts (2004) discusses the economic implication of studying EVT in its relation with risk management highlighting the need for further research on theoretical aspects of the empirical findings.

Among the empirical articles we find McNeil $(1997,1998)$ that describe parametric curvefitting methods for modelling extreme historical losses; Longin and Solnik (2001) focus on extreme correlation and find that it increases in bear markets but not in bull markets; Delfiner and Girault (2002) analyse the 'fat tails' phenomena for emerging markets and posit that measures based on EVT explains returns better than the ones based on the normal hypothesis. Malevergne et al. (2006) evaluates the use of both Pareto and Stretched-Exponential distributions to describe the 'fat tails' and found mixed results related to the generalized extreme value (GEV) estimator and the generalized Pareto distribution (GPD) estimator, with the sample size influencing the convergence toward the asymptotic theoretical distribution. LeBaron and Ritirupa (2005) analyse the significance of booms and crashes in developed and emerging Markets. Their findings are consistent with prevalent notions of crashes being more salient in emerging markets than among developed markets. Additionally, Salomon and Groetveld (2003) study risk premium in a number of international markets and suggest that investors should focus more on downside risk instead of SDs.

Harvey (1995) reports that international CAPM fails when applied to emerging markets. During the 1970s some researchers developed the 'below-target semivariance capital asset pricing model' or better known as ES-CAPM (Hogan and Warren, 1972; Hogan and Warren, 1974; Nantell and Price, 1979) which is suggested to be useful when the distribution of returns is nonnormal and nonsymmetric as is usually the case in emerging markets. Bawa and Lindenberg (1977) generalize those results and show that their model explains the data at least as well as the CAPM. Finally, Harlow and Rao (1989) derive a mean-lower partial moment (MLPM) model for any arbitrary benchmark return, which incorporates the previous models as particular cases. ${ }^{2}$ Faff $(2004)$ tests the Fama and French three-factor model using Australian data and when estimated risk premia are taken into account, the support for the model is weak.

In a article close to ours, Harvey (2000) considered the VAR as one of his 18 risk factors for developed and emerging markets. He found evidence that an asset pricing framework that incorporate skewness has success in explaining average returns. In this line of arguments, Estrada (2000) estimated returns in emerging markets using a measure of downside risk finding significant results. More recently,

\footnotetext{
${ }^{1}$ Extreme value theory provides a natural approach to VAR and ES estimation and there is already a considerable literature on the subject. See Danielsson and de Vries (1997), Embrechts et al. (1997) and Diebold et al. (1998).

${ }^{2}$ Nawrocki (1999) presents a review of such literature.
} 
Stevenson (2001) used downside risk measures to construct an optimal international portfolio while Estrada (2002) proposed the downside CAPM (DCAPM) which considers the systematic downside risk as a way to estimate the required returns in emerging markets.

Our article contains four new contributions. First we discuss efficient procedures for estimating parameters of Pareto extreme value distribution and use these results to estimate ES. Second, from a range of 21 risk measures we study their statistical relationship with observed returns. Third, we implement a factor analysis to find different components, reaching a simplified but efficient empirical model; and fourth more recent price information is used with data until the end of 2005.

\section{Theoretical Framework}

\section{Extreme value theory and expected shortfall}

Measuring risk, in some sense, is to try to summarize its distribution with a number known as risk measure. For instance, VAR is a high quantile of the distribution of losses, typically the 95th or 99th percentile. VAR provides a sort of upper bound of losses, which is expected to be exceeded in very few occasions. In EVT, we are effectively concerned about those few moments in time where this limit is exceeded, which can be very harmful for the company or portfolio. The idea is to calculate ES given by the average expected loss exceeding VAR. It was first proposed by Artzner et al. (1997) who posit that it is a coherent risk measure, while VAR is not. Then ES is the conditional expectation of loss given that loss is beyond the VAR level; i.e. ES is defined as follows:

$$
\operatorname{ES}_{\alpha}(X)=E\left[X \mid X \geq \operatorname{VAR}_{\alpha}(X)\right]
$$

Observe that if the profit-loss distribution is Normal, the VAR and the ES essentially offers the same information, as assets with a higher VAR would also have a higher ES. VAR and ES would be just scalar multiples of the SD (Yamai and Yoshiba, 2005). The problem arises when the distribution is not Normal, as tail risk may be present in the case of fat-tails and so high potential for large losses. In this case, it's crucial to identify the distribution function that best describes those extreme bad returns and one approach is to use EVT.

The modern approach to EVT is through POT models; these are models for all large observations, which exceed a high threshold. McNeil (1999) posits that POT models are considered to be the most useful for practical applications, due to their more efficient use of the limited data on extreme values. Within POT class of models we will concentrate on those related to a Frechet distribution. Much of our discussion is related to the idea of tail estimation under a power law assumption, say, we assume that returns are in the maximum domain of attraction of a Frechet distribution, so that the tail of the survival function is a power law times a slowly-varying function:

$$
P(X>x)=k(x) x^{-\alpha}
$$

As pointed out by Diebold et al. (1998), often it is assumed that $k(x)$ is constant; in which case, attention is restricted to densities with tails of the form:

$$
P(X>x)=k x^{-\alpha}
$$

defined in the domain $x \geq k^{1 / \alpha}$, with the parameters $k$ and $\alpha$ to be estimated, respectively representing the scale and shape parameters of a Pareto distribution. In this case, the first moment is given by:

$$
\mu=\left[\frac{\alpha}{\alpha-1}\right] k^{1 / \alpha}
$$

There are several ways of estimating these parameters. One of the most popular is the Hill's estimator, which is based directly on the extreme values and proceeds as follows. Order the observations $x_{(1)}>x_{(2)}>\ldots>x_{(m)}$ and form an estimator based on the difference between the $m$-th largest observation and the average of the $m$ largest observations.

$$
\hat{\alpha}=\left[\left(\frac{1}{m} \sum_{i=1}^{m} \ln \left(x_{i}\right)\right)-\ln \left(x_{m}\right)\right]^{-1}
$$

The Hill's estimator is the maximum likelihood estimator and so has good theoretical properties: it can be shown that it is consistent and asymptotically normal, assuming iid data and that $m$ grows at a suitable rate with sample size. ${ }^{3} \mathrm{~A}$ crucial problem in using the previous estimator, highlighted in Lux (2001), is to define the size of $m$, as there is an important bias-variance trade-off when varying $m$ for fixed sample size: increasing $m$, we are using more data (moving toward the centre of the distribution), which reduces the variance but increases the bias, as the power law is assumed to hold just in the extreme tail. In this article, as our main purpose is to investigate the existence of a relative risk premium among country index returns, we adopt a procedure suggested by Yamai and Yoshiba (2002) and select $m$

\footnotetext{
${ }^{3}$ See, e.g. Embrechts et al. (1997, p. 348).
} 
as the one day $\mathrm{VAR}_{95 \%}$ and $\mathrm{VAR}_{99 \%}$ for each country index.

In fact we use Hill's estimator as a reference point, but will privilege the estimation by linear regression. Simply note that

$$
P(X>x)=k x^{-\alpha}
$$

Implies,

$$
\ln P(X>x)=\ln (k)-\alpha \ln (x)
$$

so that $\alpha$ is the slope coefficient in a simple linear relationship between the log tail of the empirical survival function and the log extreme values and then we are able to estimate both $k$ and $\alpha$ by a linear regression over the survival $m$ observations.

The basic insight in this approach is that the essence of the tail estimation problem is fitting a loglinear function to a set of data, and so easy to handle and good for practical purposes. In order to verify the goodness of fit, we use mean square error (MSE), $R^{2}$, comparing the results with the ones obtained using the Hill's estimator.

Moreover, in order to calculate the ES, we know that it is related to VAR by:

$$
\mathrm{ES}_{\alpha}=\mathrm{VAR}_{\alpha}+E\left[X-\mathrm{VAR}_{\alpha} \mid X>\mathrm{VAR}_{\alpha}\right]
$$

where the second term is the mean of the excess distribution over the threshold $\mathrm{VAR}_{\alpha}$. This has the probability distribution given by the power law assumption (Pareto distribution).

\section{Risk premium}

The framework proposed in this article to infer whether there is a risk premium associated to the VAR and to ES, follows APT's basic insight. Any required return can be thought of as having two components: a risk-free rate, and a set of risk premium. The first component is compensation required for the expected loss of purchasing power, which is demanded even for a riskless asset. The second component is extra compensation for bearing risk, which depends on the asset considered, say, expected returns should include rewards for accepting risk. APT provides an approximate relation for asset returns with an unknown number of unidentified factors.

We take the perspective of a US-based, internationally diversified investor. Thus the risk-free rate should compensate this investor for the dollar's expected loss of purchasing power, and the risk premium should compensate the investor for bearing different risks (world market portfolio, extreme events, etc.). Our empirical model may be seen as an extension of Estrada (2000). We define observed return for country index $i$ as:

$\mathrm{RR}_{i}-R_{f}=a_{0}+a_{1 i}\left(\mathrm{RM}_{1 i}\right)+\cdots+a_{K i}\left(\mathrm{RM}_{K i}\right)+$ error

where $\mathrm{RR}_{i}$ is the observed dollar return, $R_{f}$ is the US risk free rate and $\mathrm{RM}_{j i}$ are risk factors $j=1, \ldots, K$, and $i$ indexes the markets. In the empirical application we use average daily observed returns in US dollars for country index $i$, which we express as $\mathrm{RR}_{i}$.

From the several risk measures available in the literature (see for instance Harvey, 2000) we choose 21 different factors, focusing on extreme risk measures like VAR and ES. The measures are:

(1) SR (systematic risk) measured by standard market's model beta and is estimated through the following 'world version' of a single factor model with $R_{m t}$ denoting the return on the MSCI world index. We estimate the following regression ${ }^{4}$ :

$$
R_{i t}-r_{f t}=\alpha_{i}+\beta_{i}\left[R_{m t}-r_{f t}\right]+e_{i t}
$$

where $r_{f t}$ is the US 3-month Treasury bill rate and $e_{i t}$ is the residual.

(2) Down- $\boldsymbol{\beta i \boldsymbol { w }}$ is the $\beta$ coefficient from market model (10) using observations when country returns and world returns are simultaneously negative.

(3) Down- $\boldsymbol{\beta} \boldsymbol{w}$ is the $\beta$ coefficient from market model (10) using observations when world returns are negative.

(4) IR (idiosyncratic risk) is the SD of residuals $e_{i t}$, in model (10)

(5) TR (total risk) is the SD of the country's index return.

(6) $\sigma-\operatorname{garch}(\mathbf{1}, \mathbf{1})$ is the volatility forecast considering a GARCH $(1,1)$ model to describe country index return's volatility.

(7) VAR95t is the parametric VAR at 95\% confidence level. The volatility considered is the one-day-ahead $\operatorname{GARCH}(1,1)$ forecast. Expected daily return is set equal to zero. One day $\mathrm{VAR}_{95 \%}$ is calculated for each index, using the expression (Jorion, 1995) given by:

$$
\mathrm{VAR}_{95 \%}=z * P V * \sigma * \sqrt{\Delta t}
$$

\footnotetext{
${ }^{4}$ We used Newey-West procedure in order to generate a covariance matrix that is consistent in the presence of both heteroskedasticity and autocorrelation of unknown form. Some recent articles like Cho and Engle (1999) Andersen et al. (2003) and Hwang and Salmon (2006) use this procedure.
} 
which in our case, considering a unit monetary investment (present value $(\mathrm{PV})=1$ ), one day investment horizon ${ }^{5}$ and a confidence level of $95 \% \quad(z=1.6448$, assuming a Normal Distribution), is equivalent to:

$$
\mathrm{VAR}_{95 \%}=1.6448 * \sigma
$$

(17) skew is the unconditional skewness of returns. It's calculated by:

$$
\text { skew }=\frac{\operatorname{Mean}\left(e_{i}^{3}\right)}{\operatorname{SD}\left(e_{i}\right)^{3}}
$$

(18) skew5\% is given by:

$\left\{\frac{(\text { return at the } 95 \text { th percentile level }- \text { mean return })-(\text { mean return }- \text { return at the } 5 \text { th percentile level })}{\text { (return at the } 95 \text { th percentile level }- \text { return at the } 5 \text { th percentile level })}\right\}$

(8) VAR95d is the empirical VAR, say the value of the observed return representing the 5th lowest percentile.

(9) VAR99t is the parametric VAR similar to VAR95 $t$ but considering a confidence interval of $99 \%$.

$$
\mathrm{VAR}_{99 \%}=2.3263 * \sigma
$$

(10) VAR99d is the empirical VAR, say the value of the observed return representing the 1st lowest percentile.

(11) ES95t is the parametric ES, given by Equations 4 and 8, using as the threshold VAR95d.

$$
\operatorname{ES} 95 t=\operatorname{VAR} 95 d+\left[\frac{\alpha}{\alpha-1}\right] k^{1 / \alpha}
$$

(12) ES95 d is the sample average of returns below the 5th percentile level (VAR95d).

It's important to point out that we are assuming ES and VAR as measures of losses and so are represented by positive numbers. In order to consider risk factors related to semi-standard deviation, we used the following expression:

Semi- $B=\sqrt{\frac{1}{T} \sum_{t=1}^{T}\left(R_{t}-B\right)^{2}}$, for all $\quad R_{t}<B$

(13) Semi-Mean is the semi SD with respect to the average return of the market. $(B=$ average return of the market)

(14) Semi-0 is the semi SD with respect to 0. $(B=0)$

(15) Semi-rf is the semi standard with respect to the risk free rate. ( $B=\mathrm{US}$ risk free rate)

(16) Kurt is the kurtosis of the return distribution.
(19) coskew1 represents coskewness definition 1 (Harvey and Siddique, 2000).

$$
\text { coskew } 1=\frac{\sum e_{i} e_{m}^{2} / T}{\sqrt{\left(\left(\sum e_{i}^{2} / T\right) *\left(\sum e_{m}^{2} / T\right)\right)}}
$$

where

$$
e_{m t}=R_{m t}-\operatorname{Avg}\left(R_{m t}\right)
$$

(20) coskew2 represents coskewness definition 2 (Harvey and Siddique, 2000).

$$
\text { coskew } 2=\frac{\sum e_{i} e_{m}^{2} / T}{\left(\sigma_{e_{m}}\right)^{3}}
$$

(21) Size which is given by the natural logarithm of the market capitalization related to each country participation in the MSCI world index. $^{6}$

For further reference, in this article, when we say beta related risk factors, we are considering the factors: SR, Down- $\beta i w$ and Down- $\beta w$; when we refer to distributional risk factors, we are considering: TR, $\sigma$-garch(1,1), VAR95t, VAR95d, VAR99t, VAR99d, ES95t, ES95d, ES99d, Semi-Mean and Semi-0; and when we refer to skewness factors we are considering skew, skew5\%, coskew1 and coskew 2 .

So, first we use the time series of each country index to calculate their individual different risk factors (for instance, the beta is estimated using Equation 10) and then we implement a cross-sectional analysis (based on Equation 9) to identify the risk premium associated to each risk factor.

\section{Methodology and Results}

In order to verify if there is a risk premium associated to the measures of risk previously discussed,

\footnotetext{
5 'The Application of Basel II to Trading Activities and the Treatment of Double Default Effects' (BIS, 2005) suggests the use of a one-to-ten days horizon in the measurement of VAR.

${ }^{6}$ Barry et al. (2002) found that mean returns for small firms exceed mean returns for large firms. Fama and French (1995) proposed size as a factor for their pricing model. This effect has been reversed in recent periods (Al-Rjoub et al. 2005).
} 
we examined a sample of daily index returns (MSCI database) for the period from 4th April 1995 to 30th December 2005. We considered the following developed markets: Australia, Austria, Belgium, Canada, Denmark, Finland, France, Germany, Ireland, Italy, Netherlands, Norway, Portugal, Spain, Sweden, Switzerland, United Kingdom, United States; and the following emerging markets: Argentina, Brazil, Chile, Colombia, Hong Kong, India, Indonesia, Israel, Jordan, Malaysia, Mexico, New Zealand, Pakistan, Peru, Philippines, Poland, Singapore, South Africa, South Korea, Taiwan, Thailand, Turkey and Venezuela. The use of country indices is to avoid the thin trading effect - the returns data impacted by censoring, when using daily data (Brooks et al., 2005).

So in the end we used 41 country indices daily dollar returns time series, the risk free rate time series and the time series of the world index also given by MSCI, representing 123376 observations. We considered the 3-month Treasury Bill yield as the risk free rate. Once we had the time series of the observed daily returns it was possible to calculate the risk factors defined in the previous Section for each country. Tables 1 and 2 list observed returns and risk factors for each market.

Surprisingly, observed average daily dollar return for emerging markets $(0.015 \%)$ is lower than for developed countries $(0.034 \%)$. This is due to the negative result offered by most Asian emerging markets (Hong Kong, India, Indonesia, Israel, Jordan, Malaysia, Pakistan, Philippines, Singapore, Taiwan and Thailand). If we exclude those countries, average observed return rises to $(0.038 \%)$. A similar result happens with beta related risk factors as they were in general higher for developed markets. It's important to notice that despite the fact that the average betas (SR) for both markets were lower than 1 , if we weight each country's beta by its size, we would reach an overall beta close to 1 . Observe that the US market represents almost $50 \%$ of the world market and has a beta of 1.141.

About the distributional risk factors, usual results are found as emerging markets present in general higher values for extreme risk measures. As usually found (Delfiner and Girault, 2002), kurtosis for both markets were higher than three pointing out to fat tails in return's distribution and this coefficient was higher for emerging markets. The skewness factors were negative for both groups, supporting previous results found in the literature (Harris et al., 2004).
In order to highlight the fat tail phenomena, in Fig. 1 we may observe the QQ plot comparing observed daily returns for the world index to the normal distribution. It can be seen that for negative extreme tail, observed returns appear more often than what is predicted by the normal distribution, especially when returns are lower than $-1.4 \%$ (aprox. equals to the VAR95d). So the normal approximation seems to perform well for the central part of the distribution but offers bad results for the tails. Recall that the kurtosis is usually higher than 3 (for the world index, kurtosis is equals to 5.747). This fact raises the need for a better understanding of the tail distribution in order to predict extreme losses. Chung et al. (2004) using US equity data from 1930 to 1998 rejected normality of returns for daily, weekly, monthly, quarterly and semi-annual intervals. In the absence of normality, we expect investors to be concerned about the shape of the tails of the distribution of portfolio returns.

We then implemented the EVT analysis. We considered $m$ as the number of failures in the VAR prediction, say when the observed return loss was greater than the empirical VAR measures (VAR95d, VAR99d). Then, we adjusted a power function to each of the instrument's excess loss time series. At this point we estimated the parameters by the two procedures described above: Hill (Maximum Likelihood Estimator) (Equation 5) and least square (LS) estimator (Equation 7). The average results for the parameters of the Pareto distribution considering all the individual stock indices are given in the Tables 3 and 4.

Figure 2 shows the graph of the Pareto Distribution considering the average LS parameters estimation for developed and emerging markets. It can be seen that the slope parameter (alpha) is higher for the developed countries' sample while the scale parameter $(k)$ is lower. This supports the evidence that extreme losses should be higher for emerging markets. For instance, the probability that in the emerging market's sample we have a daily loss over $5 \%$ is around $40 \%$, while this probability is just $14.5 \%$ for the developed countries' sample.

Table 7 provides the result of a $t$-test over the difference between the alpha parameters estimated by LS and Hill procedures. Observe that the difference is statistically different from zero, ${ }^{7}$ indicating that the estimation procedures are offering different results. In order to compare the estimation procedures we calculated the coefficient of determination $\left(R^{2}\right)$

\footnotetext{
${ }^{7}$ Considering a significance level of 0.10 .
} 


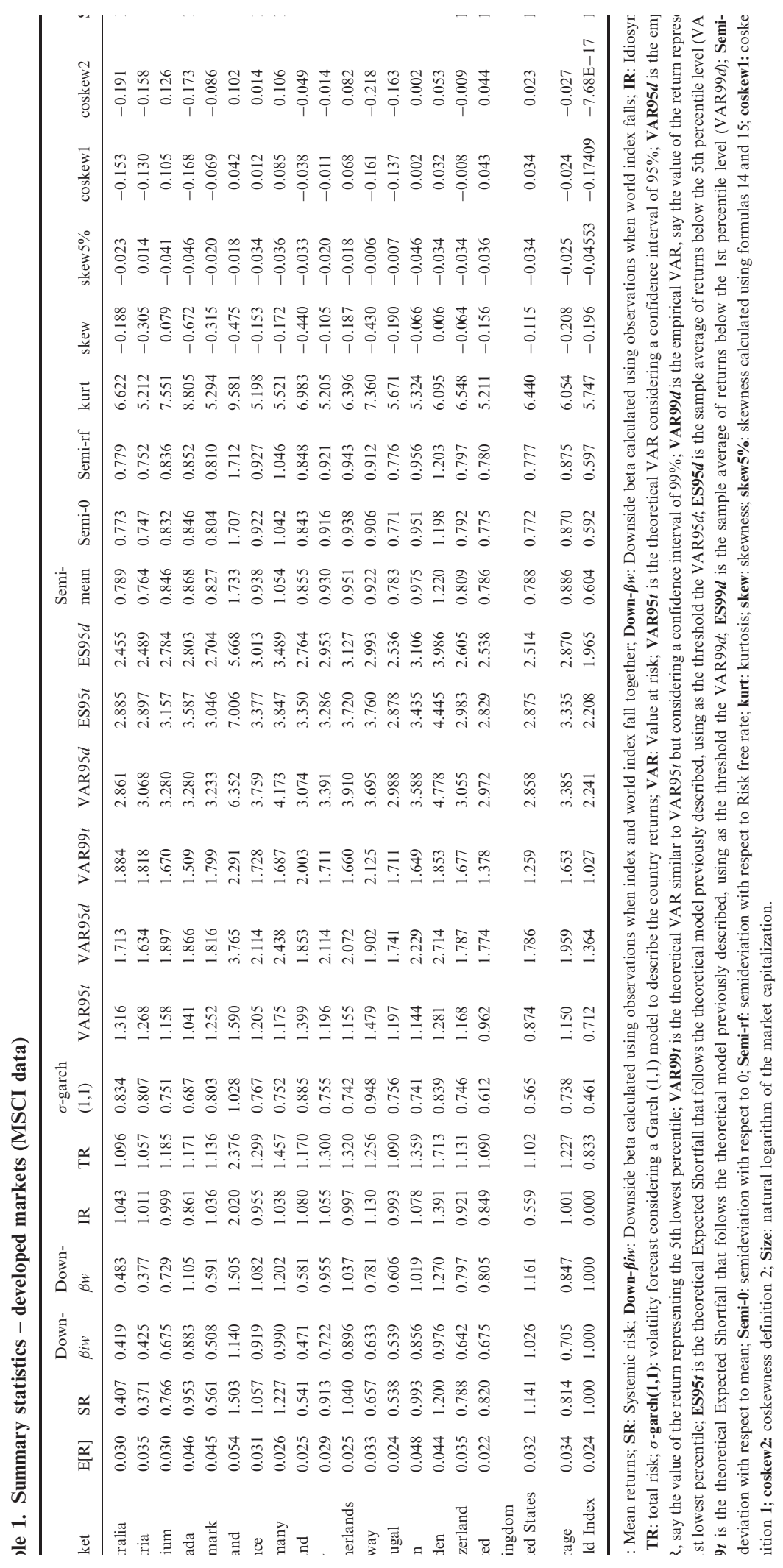




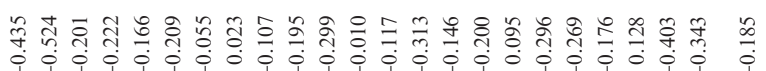

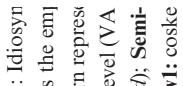

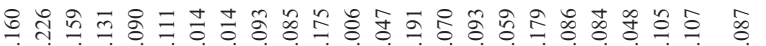

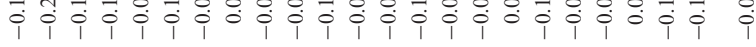

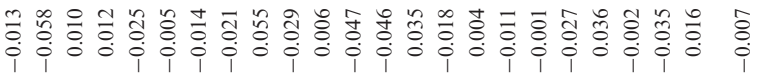

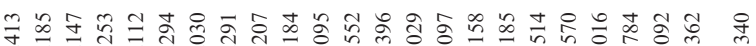

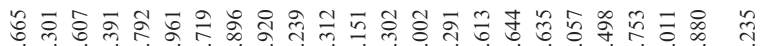

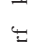

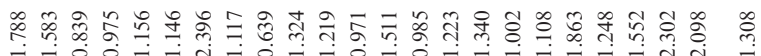

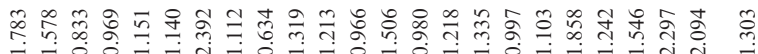
돈 웅

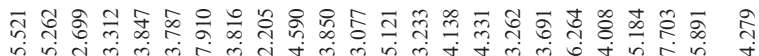

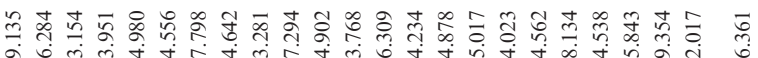

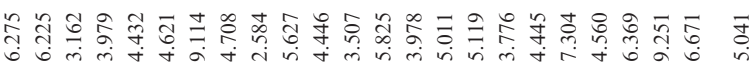

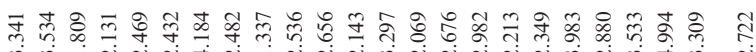

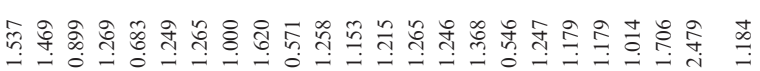

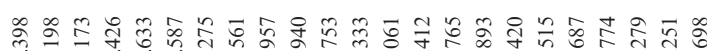

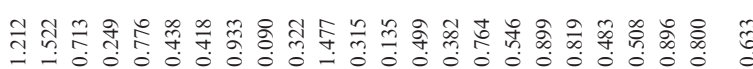
章

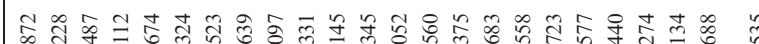

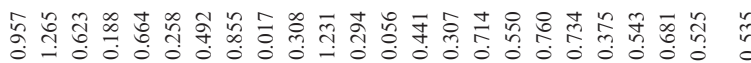

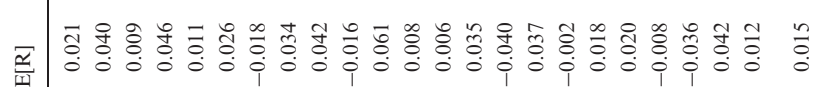

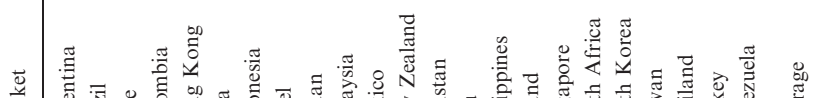

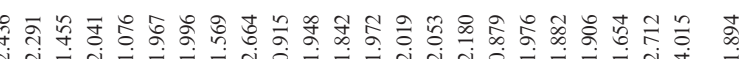

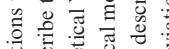

然

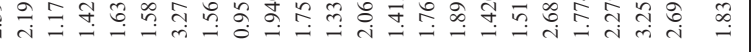

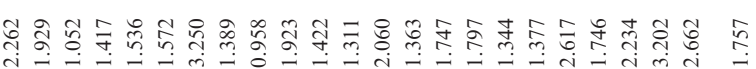

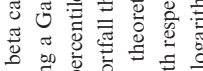

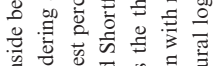

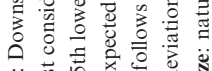

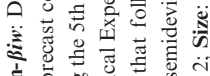

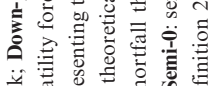

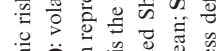

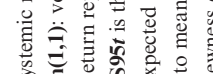

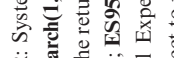

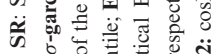

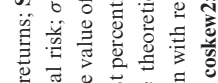
政要

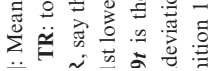




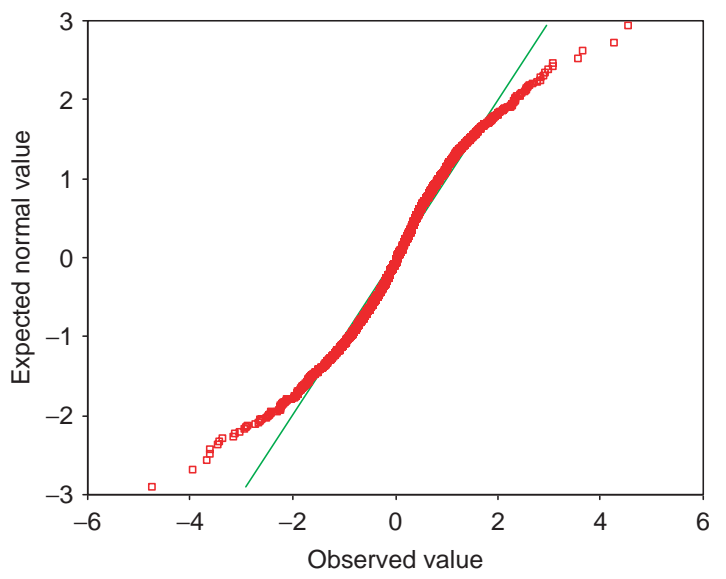

Fig. 1. Quantile-quantile graph Notes: This figure presents QQ plot comparing observed daily returns for the world index with the normal distribution.

Table 3. Summary statistics - Pareto distribution parameters (developed markets)

\begin{tabular}{llrrrr}
\hline Threshold & Parameter & Mean & Min. & Max. & SD \\
\hline \multirow{3}{*}{ VAR95d } & alpha (Hill) & 3.007 & 2.574 & 3.393 & 0.234 \\
& alpha (LS) & 2.735 & 2.121 & 3.203 & 0.341 \\
& $k$ (LS) & 9.919 & 3.881 & 27.609 & 7.183 \\
VAR99d & alpha (Hill) & 4.441 & 2.977 & 6.531 & 0.947 \\
& alpha (LS) & 3.886 & 2.396 & 5.315 & 0.994 \\
& $k$ (LS) & 362.450 & 16.202 & 2009.700 & 520.450 \\
\hline
\end{tabular}

Table 4. Summary statistics - Pareto distribution parameters (emerging markets)

\begin{tabular}{llrrrr}
\hline Threshold & Parameter & Mean & Min. & Max. & SD \\
\hline \multirow{2}{*}{ VAR95d } & alpha (Hill) & 2.712 & 1.977 & 3.443 & 0.363 \\
& alpha (LS) & 2.193 & 1.167 & 2.911 & 0.450 \\
& $k$ (LS) & 13.963 & 1.754 & 51.001 & 13.219 \\
\multirow{2}{*}{ VAR99d } & alpha (Hill) & 3.581 & 2.274 & 6.217 & 0.841 \\
& alpha (LS) & 2.784 & 0.846 & 4.435 & 0.940 \\
& $k$ (LS) & 352.340 & 4.197 & 3328.100 & 723.450 \\
\hline
\end{tabular}

for the LS estimation and the MSE for both methodologies. Average results are presented in Tables 5 and 6 .

If we consider as the threshold the VAR95d, we may observe that least squares estimator offered a better fit to the extreme losses data with a MSE much lower than the one provided by the Hill estimator. Also the $R^{2}$ for the regression used in the LS analysis was on average 0.96 again supporting the good adjustment of the Pareto distribution.

Taking VAR99d as the threshold, LS provides again better results than Hill. The $R^{2}$ greater than 0.90 supports the LS estimation of the Pareto distribution parameters. It's good to highlight that when we use the VAR99 $d$ as the threshold, we reduce the number of extreme losses of each return time series. In our case, each extreme loss series had around 28 observations instead of 150 when we used the VAR95d as the threshold.

As the LS methodology offered satisfactory results, we used the LS estimators of $\alpha$ and $k$ to define the survivor function of the extreme losses (Pareto Distribution). We calculated the parametric ES ES95t for each country following the discussed model (Equation 4). The summary results for developed and emerging markets are given in Tables 1 and 2. On average, the parametric ES ES95 $t$ measure for emerging markets was higher than the one for developed countries. Also, we may observe that the ES of the index is much lower than the one obtained just by averaging the ES for each market. For instance, ES95t is equal to 2.208 for the 


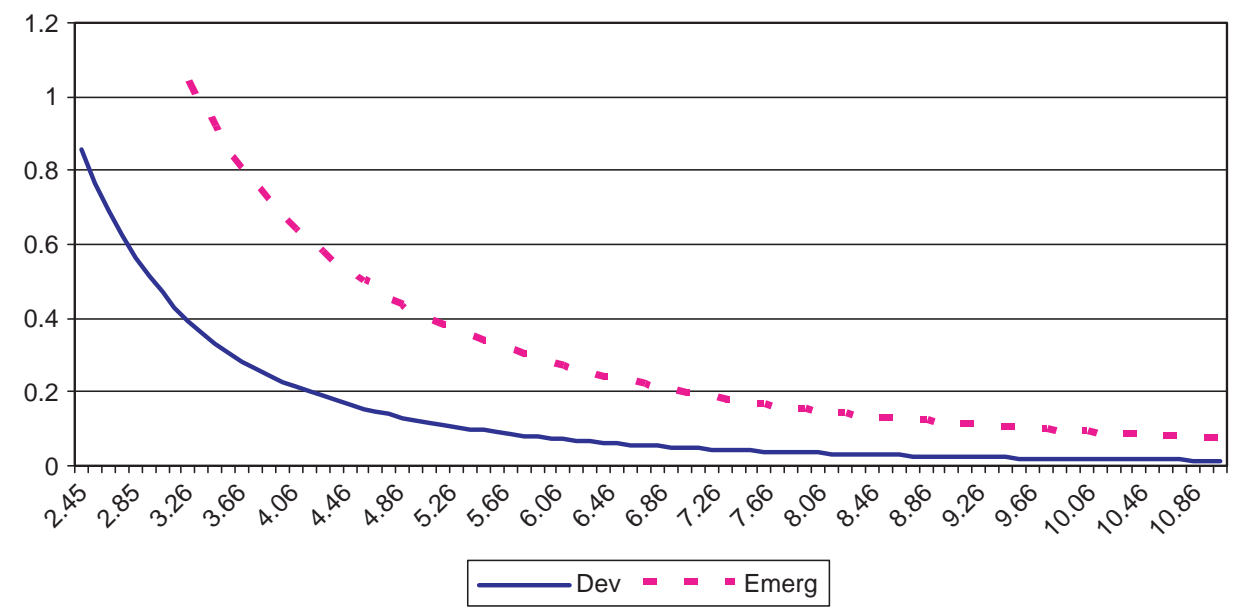

Fig. 2. Pareto distribution for developed and emerging markets

Notes: This figure represents the Pareto Distribution considering the average parameters of alpha and $k$, for the developed and emerging markets samples.

Table 5. Pareto distribution parameter estimation (developed markets)

\begin{tabular}{llllll}
\hline Threshold & Criteria & Mean & Min. & Max. & SD \\
\hline \multirow{2}{*}{ VAR95d } & R2 (LS) & 0.956 & 0.922 & 0.991 & 0.026 \\
& MSE (LS) & 0.006 & 0.001 & 0.015 & 0.004 \\
MSE(Hill) & 0.014 & 0.010 & 0.002 \\
VAR99d & R2(LS) & 0.953 & 0.875 & 0.989 & 0.031 \\
& MSE (LS) & 0.004 & 0.001 & 0.012 & 0.003 \\
\hline
\end{tabular}

Table 6. Pareto distribution parameter estimation (emerging markets)

\begin{tabular}{llllll}
\hline Threshold & Criteria & Mean & Min. & Max. & SD \\
\hline \multirow{2}{*}{ VAR95d } & R2 (LS) & 0.960 & 0.920 & 0.995 & 0.019 \\
& MSE (LS) & 0.003 & 0.000 & 0.011 & 0.028 \\
MSE (Hill) & 0.016 & 0.009 & 0.977 & 0.005 \\
VAR99d & R2 (LS) & 0.919 & 0.778 & 0.001 & 0.057 \\
& MSE (LS) & 0.005 & 0.002 & 0.020 & 0.003 \\
\hline
\end{tabular}

Table 7. Pareto distribution parameter estimation alpha (LS) - alpha (Hill)

\begin{tabular}{clllll}
\hline & Threshold & Mean & Correlation & $t$ & $p$-Value \\
\hline Developed & VAR95d & -0.272 & 0.552 & -2.795 & 0.008 \\
markets & VAR99d & -0.555 & 0.812 & -1.715 & 0.095 \\
Emerging & VAR95d & -0.519 & 0.716 & -4.302 & 0.000 \\
markets & VAR99d & -0.797 & 0.730 & -3.029 & 0.004 \\
\hline
\end{tabular}

world index (Table 1) and equals to 4.202 if we average this measure for all countries. This empirical evidence shows that the diversification effect holds for the ES.

Once we have all the risk measures defined and calculated over each market's time series, we begin the cross section regression analysis and the starting point is to compute the Pearson correlation coefficient matrix among the considered risk variables (Tables 8 and 9). These tables show the correlation matrix for developed and emerging countries. A correlation coefficient higher, in absolute terms, 


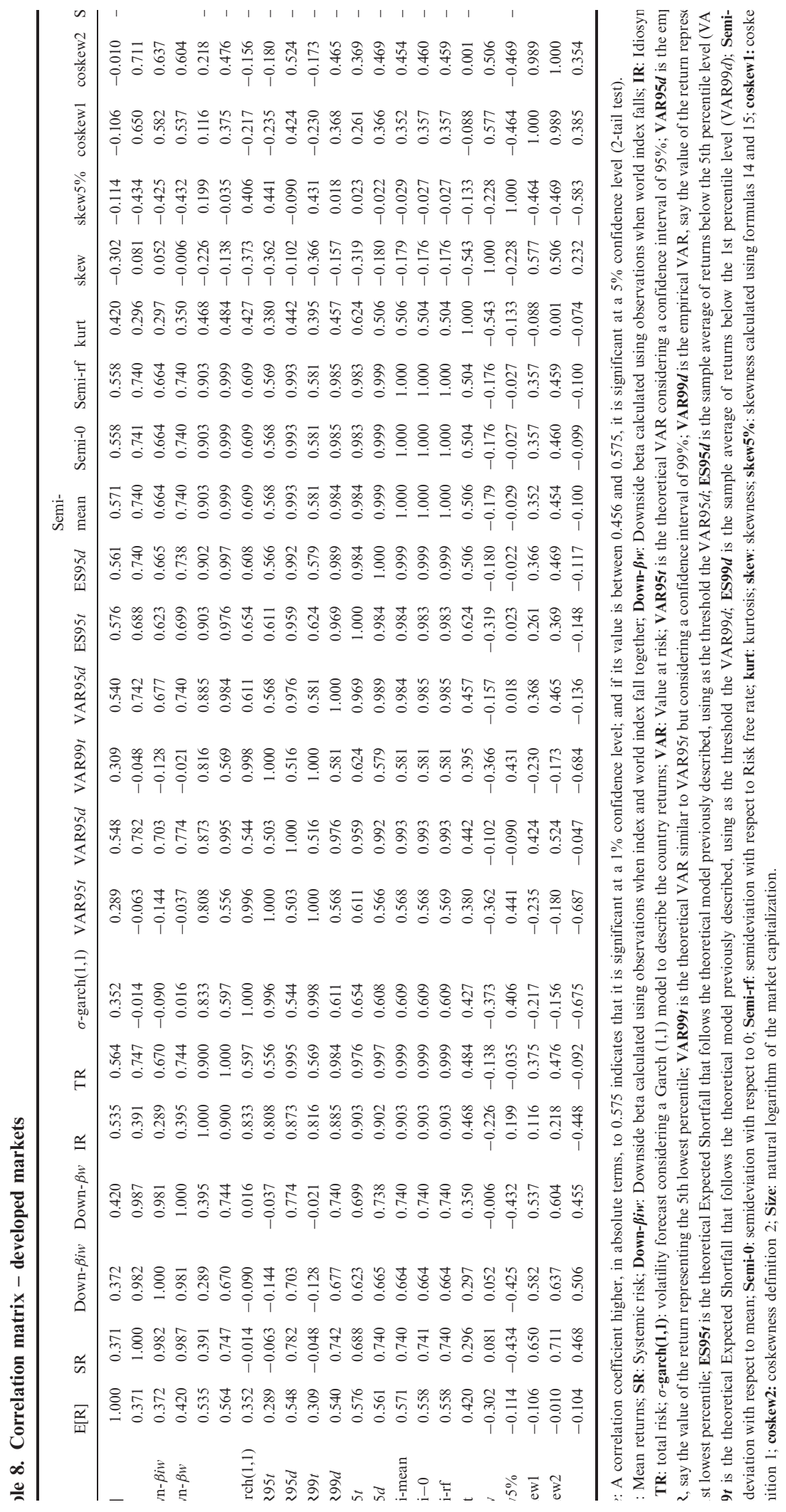




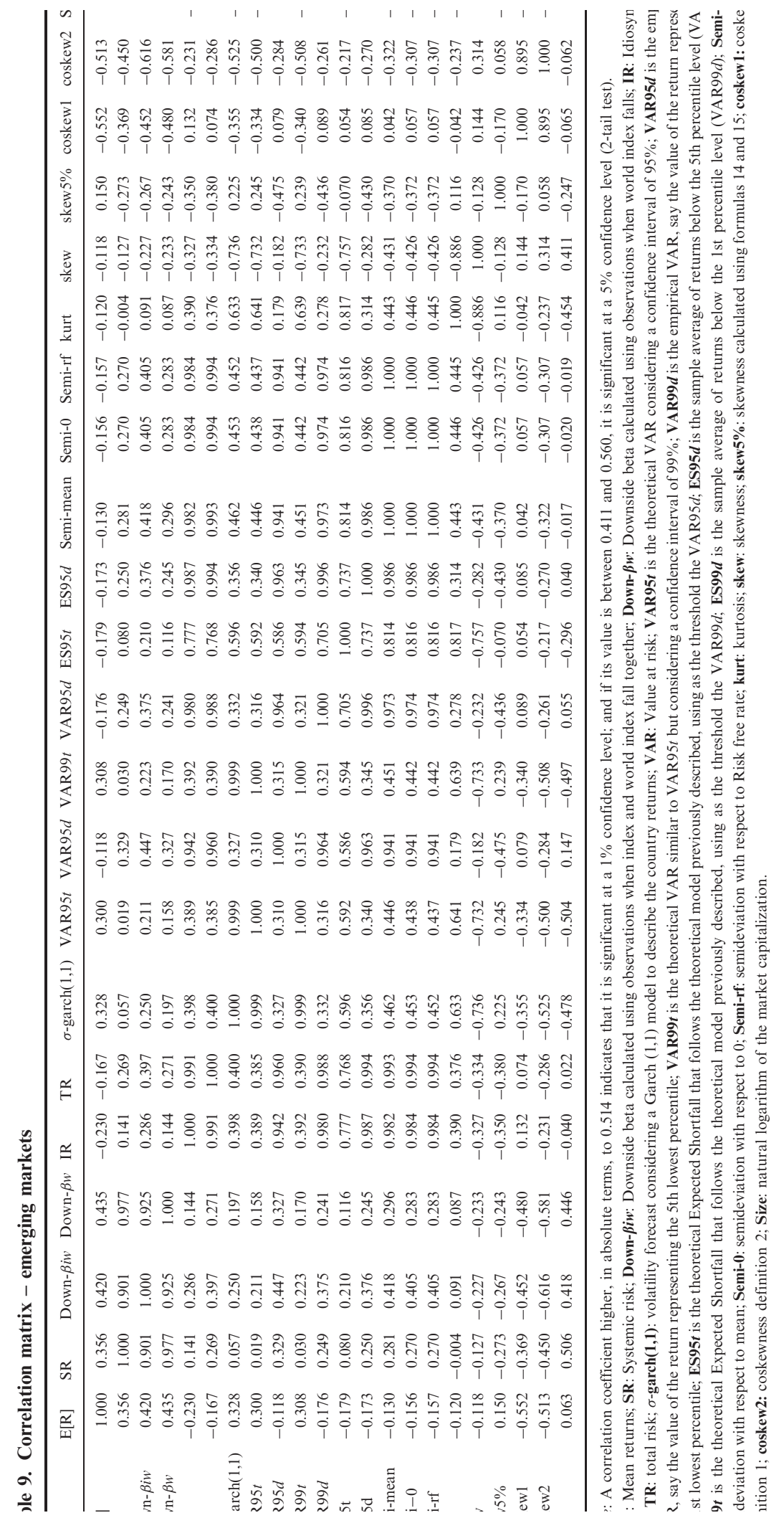


Table 10. Bivariate regressions - all markets

$$
R R_{i}=c_{0}+c_{1} * \operatorname{Risk}_{i}+u_{i}
$$

\begin{tabular}{lccccc}
\hline Risk variable & $c_{0}$ & $p$-Value & $c_{1}$ & $p$-Value & $R^{2}$ \\
\hline SR & 0.0035 & 0.6914 & 0.0286 & 0.0041 & 0.2017 \\
Down- $\beta$ iw & 0.0006 & 0.9524 & 0.0354 & 0.0058 & 0.2202 \\
Down- $\beta w$ & 0.0006 & 0.9480 & 0.0298 & 0.0024 & 0.2372 \\
IR & 0.0399 & 0.0000 & -0.0113 & 0.0434 & 0.1144 \\
TR & 0.0401 & 0.0000 & -0.0102 & 0.1038 & 0.0748 \\
$\sigma$-garch(1,1) & 0.0243 & 0.0014 & -0.0008 & 0.9089 & 0.0002 \\
VAR95t & 0.0259 & 0.0005 & -0.0015 & 0.7207 & 0.0018 \\
VAR95d & 0.0381 & 0.0009 & -0.0059 & 0.2357 & 0.0465 \\
VAR99t & 0.0255 & 0.0006 & -0.0008 & 0.7747 & 0.0011 \\
VAR99d & 0.0405 & 0.0001 & -0.0038 & 0.1134 & 0.0788 \\
ES95 $t$ & 0.0323 & 0.0000 & -0.0017 & 0.0279 & 0.0808 \\
ES95d & 0.0399 & 0.0000 & -0.0043 & 0.1072 & 0.0744 \\
Semi-mean & 0.0379 & 0.0000 & -0.0123 & 0.1283 & 0.0579 \\
Semi-0 & 0.0390 & 0.0000 & -0.0134 & 0.0966 & 0.0695 \\
Semi-rf & 0.0391 & 0.0000 & -0.0134 & 0.0965 & 0.0696 \\
kurt & 0.0260 & 0.0000 & -0.0002 & 0.0860 & 0.0450 \\
skew & 0.0230 & 0.0000 & -0.0017 & 0.6408 & 0.0072 \\
skew5\% & 0.0226 & 0.0000 & -0.0540 & 0.6694 & 0.0037 \\
coskew1 & 0.0209 & 0.0000 & -0.0409 & 0.2300 & 0.0260 \\
coskew2 & 0.0217 & 0.0000 & -0.0157 & 0.4215 & 0.0131 \\
size & -0.0004 & 0.9811 & 0.0028 & 0.0708 & 0.0617 \\
\hline
\end{tabular}

to $0.575(0.514)$ is statistically significant at a $1 \%$ confidence level; and if its value is between 0.456 $(0.411)$ and $0.575(0.514)$, it is significant at a $5 \%$ confidence level for developed (emerging) markets; considering a 2-tail test.

Taking these ranges into account we can observe some differences among both samples. Considering the correlations with the return we can see that the beta risk factors' coefficients were positive but not significant for developed markets. For emerging countries, except for SR which was not significant, the beta risk factors' coefficients were positive and significant. This initially indicates that CAPM models, based on SR, will not perform well in both samples. About the distributional risk factors, most of them offered positive and significant coefficients for developed countries, while they were negative and not significant for emerging markets. Coskewness was negative and significant for emerging markets, supporting the results found in Harvey (2000).

All previous results are in line with the general intuition that a higher risk should imply a higher return, however when we compare both samples we observe that emerging markets present higher risk and lower return when compared to the developed countries sample. At the same time the numbers suggest that the two groups of risk factors (betarelated and distributional factors) are positively (and in general significantly) correlated within each group for both samples. This empirical fact could be considered as an evidence of "home-bias' ${ }^{8}$ as market participants are investing and so requiring reward for the risk faced just within an asset group, say developed countries or emerging markets.

It's important to highlight the correlations between VAR and ES risk measures. The correlations among them in both samples were in general positive and significant, however far from one which would be the case if returns were following a Normal Distribution.

\section{Regression analysis}

We first implemented regressions considering each of the risk factors acting individually. These regressions examine the bivariate relation between the average returns and the average risk measures. Throughout all this section, we considered to be significant a $p$-value lower than 5\% and we used White (1980) heteroskedasticity consistent covariance matrix. The results related to the all markets sample are summarized in Table 10.

We can observe that the beta-related risk factors were positive and significant, explaining around $22 \%$ of the average returns. The first regression is the classic CAPM and has an $R^{2}$ equals to $20.17 \%$. Downside betas work well for the world sample

\footnotetext{
${ }^{8}$ See French and Poterba (1991) or Shapiro (1999) for a review of the home bias effect.
} 
Table 11. Bivariate regressions - developed markets

$$
R R_{i}=c_{0}+c_{1} * \mathrm{Risk}_{i}+u_{i}
$$

\begin{tabular}{lllccl}
\hline Risk variable & $c_{0}$ & $p$-Value & $c_{1}$ & $p$-Value & $R^{2}$ \\
\hline SR & 0.0244 & 0.0008 & 0.0113 & 0.1356 & 0.1374 \\
Down- $\beta$ iw & 0.0224 & 0.0060 & 0.0157 & 0.1341 & 0.1381 \\
Down- $\beta w$ & 0.0224 & 0.0028 & 0.0131 & 0.0878 & 0.1764 \\
IR & 0.0156 & 0.0113 & 0.0175 & 0.0007 & 0.2860 \\
TR & 0.0122 & 0.0193 & 0.0169 & 0.0000 & 0.3175 \\
$\sigma$-garch(1,1) & 0.0102 & 0.5373 & 0.0307 & 0.1603 & 0.1236 \\
VAR95t & 0.0145 & 0.4062 & 0.0161 & 0.2726 & 0.0838 \\
VAR95d & 0.0129 & 0.0225 & 0.0103 & 0.0002 & 0.3008 \\
VAR99t & 0.0132 & 0.4438 & 0.0120 & 0.2354 & 0.0952 \\
VAR99d & 0.0128 & 0.0230 & 0.0059 & 0.0003 & 0.2916 \\
ES95t & 0.0144 & 0.0012 & 0.0056 & 0.0000 & 0.3318 \\
ES95d & 0.0131 & 0.0076 & 0.0069 & 0.0000 & 0.3150 \\
Semi-mean & 0.0121 & 0.0134 & 0.0235 & 0.0000 & 0.3262 \\
Semi-0 & 0.0128 & 0.0121 & 0.0232 & 0.0000 & 0.3108 \\
Semi-rf & 0.0127 & 0.0132 & 0.0232 & 0.0000 & 0.3111 \\
kurt & 0.0144 & 0.2011 & 0.0031 & 0.0739 & 0.1762 \\
skew & 0.0308 & 0.0000 & -0.0151 & 0.2070 & 0.0912 \\
skew5\% & 0.0323 & 0.0000 & -0.0690 & 0.5735 & 0.0130 \\
coskew1 & 0.0338 & 0.0000 & -0.0112 & 0.6189 & 0.0113 \\
coskew2 & 0.0341 & 0.0000 & -0.0009 & 0.9648 & 0.0001 \\
Size & 0.0405 & 0.0051 & -0.0007 & 0.5947 & 0.0107 \\
\hline
\end{tabular}

Table 12. Bivariate regressions - emerging markets

$$
R R_{i}=c_{0}+c_{1} * \operatorname{Risk}_{i}+u_{i}
$$

\begin{tabular}{lrlrll}
\hline Risk variable & \multicolumn{1}{c}{$c_{0}$} & $p$-Value & \multicolumn{1}{c}{$c_{1}$} & $p$-Value & $R^{2}$ \\
\hline SR & -0.0007 & 0.9518 & 0.0287 & 0.0836 & 0.1266 \\
Down- $\beta$ iw & -0.0040 & 0.7565 & 0.0345 & 0.0469 & 0.1765 \\
Down- $\beta w$ & -0.0044 & 0.7152 & 0.0298 & 0.0284 & 0.1896 \\
IR & 0.0329 & 0.0452 & -0.0096 & 0.2684 & 0.0527 \\
TR & 0.0289 & 0.0826 & -0.0071 & 0.4010 & 0.0280 \\
$\sigma$-garch(1,1) & -0.0113 & 0.4546 & 0.0215 & 0.0868 & 0.1074 \\
VAR95t & -0.0088 & 0.5451 & 0.0122 & 0.1036 & 0.0901 \\
VAR95d & 0.0258 & 0.1816 & -0.0037 & 0.5874 & 0.0140 \\
VAR99t & -0.0096 & 0.5163 & 0.0088 & 0.0982 & 0.0951 \\
VAR99d & 0.0295 & 0.0934 & -0.0027 & 0.4115 & 0.0309 \\
ES95t & 0.0221 & 0.0156 & -0.0010 & 0.2317 & 0.0322 \\
ES95 $d$ & 0.0291 & 0.0837 & -0.0031 & 0.3950 & 0.0299 \\
Semi-mean & 0.0254 & 0.1122 & -0.0074 & 0.4988 & 0.0168 \\
Semi-0 & 0.0274 & 0.0817 & -0.0089 & 0.4127 & 0.0245 \\
Semi-rf & 0.0275 & 0.0820 & -0.0089 & 0.4120 & 0.0245 \\
kurt & 0.0171 & 0.0097 & -0.0001 & 0.2635 & 0.0144 \\
skew & 0.0145 & 0.0221 & -0.0021 & 0.4870 & 0.0139 \\
skew5\% & 0.0164 & 0.0067 & 0.1410 & 0.4120 & 0.0224 \\
coskew1 & -0.0024 & 0.7568 & -0.1941 & 0.0020 & 0.3052 \\
coskew2 & -0.0008 & 0.9180 & -0.0831 & 0.0024 & 0.2629 \\
Size & 0.0065 & 0.8066 & 0.0012 & 0.7268 & 0.0039 \\
\hline
\end{tabular}

explaining around $23 \%$ and this result comes especially from emerging markets. The intercepts are not significantly different from zero. This seems to support the CAPM. The distributional risk factors came out to be in general negative but not significant. The results for the skewness risk factors were negative but not significant. Size provided a positive but not significant result. The previous results give support to the use of the CAPM model in a world sample analysis. We performed the same analysis segregating developed and emerging markets (Tables 11 and 12). 
Table 13. Multivariate regressions - all markets

$$
R R_{i}=c_{0}+c_{1} * \mathrm{SR}_{i}+c_{2} * \mathrm{Risk}_{i}+u_{i}
$$

\begin{tabular}{lrlrlrll}
\hline SR/Risk & \multicolumn{1}{c}{$c_{0}$} & $p$-Value & \multicolumn{1}{c}{$c_{1}$} & $p$-Value & \multicolumn{1}{c}{$c_{2}$} & $p$-Value & $R^{2}$ \\
\hline Down- $\beta i w$ & 0.0007 & 0.9478 & 0.0068 & 0.7509 & 0.0279 & 0.3169 & 0.2219 \\
Down- $\beta w$ & 0.0001 & 0.9949 & -0.0286 & 0.3876 & 0.0565 & 0.0915 & 0.2483 \\
IR & 0.0187 & 0.1021 & 0.0258 & 0.0075 & -0.0090 & 0.0866 & 0.2732 \\
TR & 0.0207 & 0.0763 & 0.0293 & 0.0022 & -0.0108 & 0.0645 & 0.2859 \\
$\sigma$-garch(1,1) & -0.0040 & 0.7123 & 0.0304 & 0.0016 & 0.0062 & 0.3639 & 0.2125 \\
VAR95t & -0.0029 & 0.7845 & 0.0303 & 0.0016 & 0.0033 & 0.4348 & 0.2096 \\
VAR95d & 0.0205 & 0.1109 & 0.0307 & 0.0017 & -0.0074 & 0.1270 & 0.2748 \\
VAR99 $t$ & -0.0032 & 0.7625 & 0.0303 & 0.0016 & 0.0024 & 0.4128 & 0.2104 \\
VAR99d & 0.0209 & 0.0806 & 0.0291 & 0.0022 & -0.0040 & 0.0796 & 0.2870 \\
ES95t & 0.0121 & 0.2175 & 0.0274 & 0.0047 & -0.0015 & 0.0506 & 0.2639 \\
ES95d & 0.0204 & 0.0803 & 0.0293 & 0.0022 & -0.0046 & 0.0657 & 0.2847 \\
Semi-mean & 0.0188 & 0.2723 & 0.0296 & 0.0021 & -0.0136 & 0.0712 & 0.2723 \\
Semi-0 & 0.0196 & 0.0836 & 0.0294 & 0.0021 & -0.0144 & 0.0563 & 0.2819 \\
Semi-rf & 0.0197 & 0.0830 & 0.0294 & 0.0021 & -0.0144 & 0.0563 & 0.2820 \\
Kurt & 0.0063 & 0.4875 & 0.0274 & 0.0054 & -0.0001 & 0.1373 & 0.2266 \\
Skew & 0.0033 & 0.7151 & 0.0284 & 0.0038 & -0.0012 & 0.6529 & 0.2054 \\
skew5\% & 0.0028 & 0.7342 & 0.0003 & 0.0003 & 0.1481 & 0.2626 & 0.2241 \\
coskew1 & -0.0036 & 0.7079 & 0.0325 & 0.0017 & -0.0693 & 0.0239 & 0.2728 \\
coskew2 & -0.0015 & 0.8824 & 0.0311 & 0.0033 & -0.0282 & 0.2424 & 0.2424 \\
Size & 0.0062 & 0.6683 & 0.0301 & 0.0020 & -0.0004 & 0.7561 & 0.2026 \\
\hline
\end{tabular}

From these tables, we have evidence that CAPM doesn't perform well in both samples taken apart. As pointed out in Estrada (2000), the lack of explanatory power of beta can be explained by: the markets are not fully integrated; the world-market portfolio is not mean-variance efficient; the model is mispecified; and finally, returns and betas may be uncorrelated if these two magnitudes are summarized by long-term averages but their true values change over time. In the multivariate regressions we could see that adding another risk variable (like VAR95t for the case of developed markets) the SR (beta) became significant.

Considering the developed countries sample, distributional risk measures were in general positive and significant explaining up to $33.18 \%$ (in the case of ES95t) of the returns variation, indicating the relevance of downside extreme risk for sophisticated markets. VAR, ES and Semi-deviation measures are important and priced in developed countries. Related to skewness risk factors, just skew $5 \%$, which is correlated to distributional risk measures, offered a positive and significant coefficient.

In the case of emerging markets, downside betas and coskewness' measures were significant explaining in the case of coskew1 $30.52 \%$. Estrada (2000) already has shown the relevance of down-side beta for emerging markets. In terms of coskewness, as suggested in Harvey and Siddique (2000), if asset returns have systematic skewness, expected returns should include rewards for accepting this risk.
Emerging markets exhibit a more skewed return distribution and so we found significant coefficients for this risk measure. Also note that in a world where investors care about skewness of their portfolios, coskewness should count and skewness itself should not (this is similar to the roles played by beta and volatility in the classic CAPM). This is what we found for emerging markets.

On the other hand, IR and TR were not significant for emerging markets, however were priced in developed countries. Asset pricing theory predicts that only systematic variance should be priced but $31.75 \%$ of the developed countries' return was explained by total variance.

As the usual beta came out to be significant in the bivariate regression, considering the whole sample, we decided to investigate multivariate possibilities. The following regressions use two risk factors ( $\mathrm{SR}+$ another risk measure). Tables $13-15$ provide the results for the whole sample, developed markets and emerging markets, respectively.

When we considered all countries in the sample, the multivariate regressions don't seem to improve the CAPM analysis as we remain with an explanation $\left(R^{2}\right)$ of around $27 \%$, due to the beta and together with it, just coskew1 risk factor was negative and statistically significant. Kurtosis, skewness and size were negative but not significant. However when we segregate the sample we find better results for developed countries, with the $R^{2}$ raising up to around $34.67 \%$. The distributional risk factors were 
Table 14. Multivariate regressions - developed markets

$$
\mathrm{RR}_{i}=c_{0}+c_{1} * \mathrm{SR}_{i}+c_{2} * \mathrm{Risk}_{i}+u_{i}
$$

\begin{tabular}{lllrlrll}
\hline SR/Risk & $c_{0}$ & $p$-Value & \multicolumn{1}{c}{$c_{1}$} & $p$-Value & \multicolumn{1}{c}{$c_{2}$} & $p$-Value & $R^{2}$ \\
\hline Down- $\beta$ iw & 0.0232 & 0.0120 & 0.009 & 0.8917 & 0.0091 & 0.8500 & 0.1390 \\
Down- $\beta$ w & 0.0201 & 0.0102 & -0.0539 & 0.0578 & 0.0675 & 0.0199 & 0.2546 \\
IR & 0.0132 & 0.0103 & 0.0058 & 0.3309 & 0.0151 & 0.0045 & 0.3168 \\
TR & 0.0119 & 0.0202 & -0.0035 & 0.6679 & 0.0194 & 0.0036 & 0.3233 \\
$\sigma$-garch(1,1) & 0.0000 & 0.9991 & 0.0114 & 0.0491 & 0.0312 & 0.0259 & 0.2646 \\
VAR95t & 0.0027 & 0.8249 & 0.0119 & 0.0483 & 0.0175 & 0.0655 & 0.2356 \\
VAR95d & 0.0123 & 0.0236 & -0.0046 & 0.6028 & 0.0125 & 0.0075 & 0.3097 \\
VAR99 $t$ & 0.0018 & 0.8748 & 0.0118 & 0.0480 & 0.0127 & 0.0502 & 0.2441 \\
VAR99d & 0.0126 & 0.0245 & -0.0020 & 0.7950 & 0.0065 & 0.0087 & 0.2936 \\
ES95 $t$ & 0.0145 & 0.0020 & -0.0015 & 0.8335 & 0.0059 & 0.0005 & 0.3331 \\
ES95d & 0.0129 & 0.0072 & -0.0030 & 0.7011 & 0.0078 & 0.0024 & 0.3195 \\
Semi-Mean & 0.0119 & 0.0131 & -0.0035 & 0.6555 & 0.0270 & 0.0016 & 0.3322 \\
Semi-0 & 0.0126 & 0.0113 & -0.0029 & 0.7167 & 0.0261 & 0.0025 & 0.3148 \\
Semi-rf & 0.0125 & 0.0123 & -0.0028 & 0.7172 & 0.0261 & 0.0025 & 0.3150 \\
kurt & 0.0110 & 0.3041 & 0.0082 & 0.1997 & 0.0025 & 0.1026 & 0.2428 \\
skew & 0.0200 & 0.0016 & 0.0121 & 0.0628 & -0.0168 & 0.0532 & 0.2483 \\
skew5\% & 0.0247 & 0.0005 & 0.0120 & 0.1600 & 0.0350 & 0.8149 & 0.1401 \\
coskew1 & 0.0126 & 0.0785 & 0.0232 & 0.0050 & -0.0634 & 0.0041 & 0.3467 \\
coskew2 & 0.0128 & 0.1012 & 0.0233 & 0.0106 & -0.0470 & 0.0124 & 0.2892 \\
size & 0.0419 & 0.0016 & 0.0163 & 0.0208 & -0.0022 & 0.0637 & 0.2355 \\
\hline
\end{tabular}

Table 15. Multivariate regressions - emerging markets

\begin{tabular}{lrlrlrll}
\multicolumn{7}{l}{$R R_{i}=c_{0}+c_{1} * \mathrm{SR}_{i}+c_{2} * \mathrm{Risk}_{i}+u_{i}$} \\
\hline SR/Risk & \multicolumn{1}{l}{$c_{0}$} & $p$-Value & \multicolumn{1}{c}{$c_{1}$} & $p$-Value & \multicolumn{1}{c}{$c_{2}$} & $p$-Value & $R^{2}$ \\
\hline Down- $\beta i w$ & -0.0036 & 0.7838 & -0.0097 & 0.7532 & 0.0434 & 0.1680 & 0.1792 \\
Down- $\beta w$ & -0.0032 & 0.7685 & -0.1217 & 0.0659 & 0.1307 & 0.0188 & 0.2945 \\
IR & 0.0194 & 0.3136 & 0.0319 & 0.0225 & -0.0120 & 0.1646 & 0.2065 \\
TR & 0.0189 & 0.3274 & 0.0348 & 0.0146 & -0.0121 & 0.1735 & 0.2013 \\
$\sigma$-garch(1,1) & -0.0249 & 0.1056 & 0.0272 & 0.0789 & 0.02 & 0.0898 & 0.2213 \\
VAR95t & -0.0240 & 0.1154 & 0.0282 & 0.0684 & 0.0119 & 0.2128 & 0.2128 \\
VAR95d & 0.0188 & 0.4015 & 0.0357 & 0.0160 & -0.0083 & 0.2926 & 0.1888 \\
VAR99t & -0.0243 & 0.1124 & 0.0279 & 0.0713 & 0.0085 & 0.0970 & 0.2153 \\
VAR99d & 0.0190 & 0.3422 & 0.0343 & 0.0156 & -0.0043 & 0.2012 & 0.2012 \\
ES95t & 0.0065 & 0.6413 & 0.0300 & 0.0507 & -0.0012 & 0.1744 & 0.1701 \\
ES95d & 0.0185 & 0.3388 & 0.0343 & 0.0158 & -0.0050 & 0.1802 & 0.1997 \\
Semi-mean & 0.0156 & 0.4030 & 0.0343 & 0.0168 & 60.403 & 0.2035 & 0.1840 \\
Semi-0 & 0.0171 & 0.3550 & 0.0346 & 0.0145 & 10.355 & 0.1656 & 0.1954 \\
Semi-rf & 0.0172 & 0.3533 & 0.0346 & 0.0144 & 30.0346 & 0.1653 & 0.1956 \\
kurt & 0.0011 & 0.9269 & 0.0286 & 0.0771 & -0.0001 & 0.2707 & 0.1406 \\
skew & -0.0008 & 0.9493 & 0.0279 & 0.0901 & -0.0013 & 0.5846 & 0.1320 \\
skew5\% & -0.0021 & 0.8496 & 0.0345 & 0.0205 & 0.2509 & 0.1503 & 0.1924 \\
coskew1 & -0.0082 & 0.4139 & 0.0142 & 0.4063 & -0.1713 & 0.0151 & 0.3319 \\
coskew2 & -0.0056 & 0.6153 & 0.0126 & 0.5240 & -0.0717 & 0.0316 & 0.2825 \\
size & 0.0177 & 0.4961 & 0.0351 & 0.0285 & -0.0029 & 0.3319 & 0.1451 \\
\hline
\end{tabular}

positive and significant. Beta factor became significant when considered together with $\sigma$-garch $(1,1)$, VAR95t, VAR99t, coskew1, coskew2 and Size.
In emerging markets, beta became positive and significant in most regressions, explaining around $20 \%$, however, Down- $\beta w$, coskew1 and coskew2 
Table 16. Principal components

\begin{tabular}{|c|c|c|c|}
\hline Risk factor & AII & Dev. & Emerg. \\
\hline SR & 2 & 1 or 2 & 3 \\
\hline Down- $\beta i w$ & 2 & 1 or 2 & 1 or 3 \\
\hline Down- $\beta w$ & 2 & 1 or 2 & 3 \\
\hline IR & 1 & 1 & 1 \\
\hline TR & 1 & 1 & 1 \\
\hline$\sigma-\operatorname{garch}(1,1)$ & 1 & 1 or 2 & 1 or 2 \\
\hline VAR95t & 1 & 1 or 2 & 1 or 2 \\
\hline VAR95d & 1 & 1 & 1 \\
\hline VAR99 $t$ & 1 & 1 or 2 & 1 or 2 \\
\hline VAR99d & 1 & 1 & 1 \\
\hline $\mathrm{ES} 95 t$ & 1 & 1 & 1 \\
\hline $\mathrm{ES} 95 d$ & 1 & 1 & 1 \\
\hline Semi-mean & 1 & 1 & 1 \\
\hline Semi-0 & 1 & 1 & 1 \\
\hline Semi-rf & 1 & 1 & 1 \\
\hline kurt & 1,3 or 4 & 1 or 3 & 1,2 or 4 \\
\hline skew & 1,3 or 4 & 2 or 3 & 1,2 or 4 \\
\hline skew $5 \%$ & 2 & 2 & 2 \\
\hline coskew1 & 3 or 4 & 2 or 3 & 3 or 4 \\
\hline coskew2 & 1,3 or 4 & 1,2 or 3 & 1,3 or 4 \\
\hline Size & 1 or 2 & 2 & 2 \\
\hline
\end{tabular}

offered better results and in these cases beta was not significant. ${ }^{9}$

As a last analysis, we addressed the several risk measures presented before and, using a principal components approach, tried to identify if they load in different factors or are offering the same information. We can observe from the Tables 8 and 9 that there is a high correlation among groups of risk factors, which would lead us to initially suppose the existence of two risk components, one related to the market risk and the other dealing with the distributional characteristics. An important result to highlight is the positive and significant correlation between the observed ES and the one using the model presented in this article, specially for developed countries (0.984), again supporting the use of the Pareto approximation to describe the tail distribution. When we run a principal components' analysis over the 21 risk factors we find the results presented in Table 16.

The principal components analysis offered four factors for the all countries sample; one related to beta, another related to a distributional characteristic and the remaining two linked to kurtosis and skewness measures. The results for developed and emerging markets are mixed reaching three and four factors, respectively. Recall that distributional risk factors in general were not significant for the emerging market's sample.

Summing up, the empirical evidence suggests that returns extreme distributional characteristics have a risk-premium associated with them in developed markets. In the case of emerging markets, it is coskewness measures and, to a lower degree, downside betas which are correlated with observed returns.

\section{Conclusions}

In this article, we had four main goals: first discuss efficient procedures for estimating parameters of Pareto extreme value distribution and use these results to estimate ES; second, from a range of 21 risk measures we studied their statistical relationship with observed returns; third, we implemented a factor analysis to find different components, reaching a simplified but efficient empirical model; and fourth more recent price information was used with data until the end of 2005 and the results were compared with previous works (Estrada, 2000; Harvey, 2000). We used daily data from 41 emerging and developed countries, in the period from 1995 to 2005.

Surprisingly, over a 10 years period, observed average daily dollar return for emerging markets $(0.015 \%)$ is lower than the one for developed countries $(0.034 \%)$ whereas TR is higher in emerging $(1.833 \%)$ than in developed $(1.227 \%)$ countries. This fact challenges conventional wisdom. The findings support the use of a Pareto distribution to describe the tails and the log linear regression estimation of its parameters, as a better procedure if compared to the Hill's estimator (Maximum Likelihood Estimator). Related to the risk premium, we observed a significant relationship between observed returns and extreme distributional characteristics for developed countries, but not for emerging markets. CAPM seems to be supported when we consider the whole sample but fails when we segregate the markets. The results also support the use of coskewness as a risk measure in line of the Harvey and Siddique (2000) model, especially for emerging markets. The factor analysis for all countries indicated four components: one related to beta, another related

\footnotetext{
${ }^{9}$ We also tried to improve the model introducing in the regression the size of each country's market. A three-factor model was fitted where two of them are beta and the natural logarithm of the market capitalization. The coefficient for size was negative in almost all regressions suggesting that small markets get a premium. However, due to colinearity problems results are of dubious statistical significance. Full results are available on request.
} 
to distributional risk factors and the others mixed among the kurtosis and coskewness variables.

It is important to highlight that the explanation of the cross section of average returns remains a puzzle, as we were able to explain in the multivariate situation no more than $35 \%$ of the variation in returns. This level of explanation is usually what one gets when uses Capital Asset Pricing Model (CAPM) or Arbitrage Pricing Theory (APT) based models like us. So, an avenue of opportunities is open by extending these models to accept for instance behavioural aspects, relaxing the assumption about completely rational (risk-averse) market participants as suggested in Barberis and Thaler (2003).

\section{Acknowledgements}

The views expressed in this work are those of the authors and do not reflect those of the Banco Central do Brasil or its members. We would like to thank an unknown reviewer, Javier Perote, Alfonso Novales and seminar participants at XIII Foro de Finanzas. This research was funded by MEC Grants BEC2002-0279 and SEJ2005-05485. The usual disclaimers apply.

\section{References}

Al-Rjoub, S., Varela, O. and Hassan, M. (2005) The size effect reversal in the USA, Applied Financial Economics, 15, 1189-97.

Andersen, T. G., Bollerslev, T., Diebold, F. X. and Wu, J. (2004) Realized beta: persistence and predictability, Manuscript, Northwestern University, Duke University and University of Pennsylvania.

Artzner, P., Delbaen, F., Eber, J. and Heath, D. (1997) Thinking coherently, RISK, 10, 68-71.

Basel Committee on Banking Supervision (2005) The application of Basel II to trading activities and the treatment of double default effects, Bank For International Settlements (BIS).

Barberis, N. and Thaler, R. (2003) A survey of behavioral finance, in Handbook of the Economics of Finance, 1st Edn, Vol. 1 (Eds) G. M. Constantinides, M. Harris, and R. Stulz, Elsevier, North Holland, pp. 1053-128.

Barry, C., Goldreyer, E., Lockwood, L. and Rodriguez, M. (2002) Robustness of size and value effects in emerging equity markets, 1985-2000, Emerging Markets Review, 3, $1-30$.

Bawa, V. and Lindenberg, E. (1977) Capital market equilibrium in a mean-lower partial moment framework, Journal of Financial Economics, 5, 189-200.

Brooks, R., Faff, R., Fry, T. and BissoondoyalBheenick, E. (2005) Alternative beta risk estimators in cases of extreme thin trading: Canadian evidence, Applied Financial Economics, 15, 1251-58.
Cho, Y. H. and Engle, R. (1999) Time-varying betas and asymmetric effects of news: empirical analysis of blue chips stocks, NBER Working Paper Series (7330).

Chung, P., Johnson, H. and Schill, M. (2006) Asset pricing when returns are nonnormal: Fama-French factors vs. higher-order systematic co-moments, Journal of Business, 79, 923-40.

Danielsson, J. and de Vries, C. (1997) Tail index and quantile estimation with very high frequency data, Journal of Empirical Finance, 4, 241-57.

Delfiner, M. and Girault, M (2002) Aplicacion de la teoria de valores extremos al gerenciamiento del riesgo. UCEMA Working Paper No. 217.

Diebold, F. X., Schuermann, T. and Stroughair, J. (1998) Pitfalls and opportunities in the use of extreme value theory in risk management, in Advances in Computational Finance, (Eds.) A.-P. N. Refenes, J. D. Moody and A. N. Burgess, Kluwer Academic Publishers, Amsterdam, pp. 3-12. Reprinted in Journal of Risk Finance, 1, 30-6.

Embrechts, P. (2004) Extremes in economics and the economics of extremes, in Extreme Values in Finance, Telecommunications and the Environment (Eds) B. Finkenstädt and H. Rootzén, Chapman and Hall CRC, London, pp. 169-83.

Embrechts, P., Klüppelberg, C. and Mikosch, T. (1997) Modelling Extremal Events for Insurance and Finance, Springer, Berlin.

Estrada, J. (2000) The cost of equity in emerging markets: a downside risk approach, Emerging Markets Quarterly, 4, 19-30.

Estrada, J. (2002) Systematic risk in emerging markets: the D-CAPM, Emerging Markets Review, 3, 365-79.

Faff, R. (2004) A simple test of the Fama and French model using daily data: Australian evidence, Applied Financial Economics, 14, 83-92.

Fama, E. and French, K. (1995) Size and book-to-market factors in earnings and returns, The Journal of Finance, 50, 131-55.

French, K. and Poterba, J. (1991) Investor diversification and international equity markets, American Economic Review, 81, 222-26.

Harlow, V. and Rao, R. (1989) Asset pricing in a generalized mean-lower partial moment framework: theory and evidence, Journal of Financial and Quantitative Analysis, 24, 285-311.

Harris, R., Küçüközmen, C. and Yilmaz, F. (2004) Skewness in the conditional distribution of daily equity returns, Applied Financial Economics, 14, 195-202.

Harvey, C. (1995) The risk exposure of emerging equity markets, The World Bank Economic Review, 9, 19-50.

Harvey, C. (2000) The drivers of expected returns in international markets, Emerging Markets Quarterly, 4, 32-49.

Harvey, C. and Siddique, A. (2000) Conditional skewness in asset pricing tests, The Journal of Finance, 55, 1263-95.

Hogan, W. and Warren, J. (1972) Computation of the efficient boundary in the E-S portfolio selection model, Journal of Financial and Quantitative Analysis, 7, 1881-96.

Hogan, W. and Warren, J. (1974) Toward the development of an equilibrium capital-market model based on semivariance, Journal of Financial and Quantitative Analysis, 9, 1-11. 
Hwang, S. and Salmon, M. (2006) Sentiment and beta herding, behavioural finance and market efficiency, Warwick Business School.

Jorion, P. (1995) Value at Risk, Irwin, McGraw Hill, New York.

LeBaron, B. and Ritirupa, S. (2005) Extreme value theory and fat tails in equity markets. Available online at SSRN: http://ssrn.com/abstract $=873656$ (Accessed March 2006).

Longin François y Solnik Bruno. (2001) Extreme correlation of international equity markets, The Journal of Finance, 56, 649-76.

Lux, T. (2001) The limiting extremal behavior of speculative returns: an analysis of intra-daily data from the Francfurt Stock Exchange, Applied Financial Economics, 11, 299-315.

McNeil, A. (1997) Estimating the tails of loss severity distributions using extreme value theory, ASTIN Bulletin, 27, 1117-37.

McNeil, A. (1998) Calculating quantile risk measures for financial time series using extreme value theory. Manuscript, Department of Mathematics, ETH, Swiss Federal Technical University, Zurich, Switzerland.

McNeil, A. (1999) Extreme value theory for risk managers, Internal Modelling and CAD II published by RISK Books, London, pp. 93-113.

Malevergne, Y., Pisarenko, V. and Sornette, D. (2006) On the power of generalized extreme value (GEV) and generalized Pareto distribution (GPD) estimators for empirical distributions of stock returns, Applied Financial Economics, 16, 271-89.

Nantell, T. and Price, B. (1979) An analytical comparison of variance and semivariance capital market theories, Journal of Financial and Quantitative Analysis, 14, 221-42.

Nawrocki, D. (1999) A brief story of downside risk measures, Journal of Investing, fall, 9-25.

Salomons, R. and Grootveld, H. (2003) The equity risk premium: emerging vs. developed markets, Emerging Markets Review, 4, 121-44.

Shapiro, A. (1999) Multinational Financial Management, John Wiley \& Sons, New York.

Stevenson, D. (2001) Emerging markets, downside risk and the asset allocation decision, Emerging Markets Review, 2, 50-66.

Yamai, Y. and Yoshiba, T. (2002) Comparative analysis of expected shortfall and Value-at-Risk: their estimation error, decomposition and optimization, Institute of Monetary and Economic Studies, Bank of Japan, 20, 87-122.

Yamai, Y. and Yoshiba, T. (2005) Value-at-Risk versus expected shortfall: a practical perspective, Journal of Banking and Finance, 29, 997-1015.

White, H. (1980) A heteroskedasticity-consistent covariance matrix estimator and a direct test for heteroskedasticity, Econometrica, 48, 817-38. 